\title{
Tumor sincrónico renal: asociación de adenocarcinoma renal y tumor transicional de pelvis renal, en el mismo riñon, un hallazgo excepcional
}

\author{
I. Gómez García, R. Rodríguez Patrón, S. Conde Someso, E. Sanz Mayayo, R. García Navas, \\ A. Palmeiro*
}

Servicio de Urología, *Servicio de Anatomía Patológica. Hospital Ramón y Cajal. Madrid.

Actas Urol Esp 2005; (7): 711-714

\section{RESUMEN}

TUMOR SINCRÓNICO RENAL: ASOCIACIÓN DE ADENOCARCINOMA RENAL Y TUMOR TRANSICIONAL DE PELVIS RENAL, EN EL MISMO RIÑÓN, UN HALLAZGO EXCEPCIONAL

El tumor de células renales supone el $1 \%$ de los tumores del adulto, mientras que el carcinoma transicional tiene una incidencia del 7\%. La aparición simultánea de un carcinoma de células renales, y un tumor transicional de pelvis en el mismo riñón, suponen un hecho excepcional no existiendo más de 30 casos publicados en el mundo, presentando una incidencia aproximada del 0,14\% de la patología tumoral renal. Presentamos un nuevo caso de esta inusual asociación que supone el 4 caso referenciado en la literatura en español.

Palabras clave: Tumor sincrónico renal. Carcinoma de células renal. Carcinoma transicional. Literatura en español.

\section{ABSTRACT}

RENAL SYNCHRONOUS TUMOR: ASSOCIATION DE RENAL ADENOCARCINOMA AND TRANSITIONAL TUMOR OF RENAL PELVIS, IN THE SAME KIDNEY, AN EXCEPTIONAL DISCOVERY

The renal cell tumour supposes $1 \%$ of the adult's tumors, while the transitional carcinoma has an incidence of $7 \%$. The simultaneous appearance of a carcinoma of renal cells, and a transitional tumour of pelvis in the same kidney, they suppose an exceptional fact not existing but of 30 cases published in the world, presenting an approximate incidence of $0.14 \%$ of the pathology renal tumoral. We present a new case of this unusual association that supposes the 4 case indexed in the literature in Spanish.

Keywords: Renal synchronous tumour. Renal carcinoma of cells. Transitional carcinoma.

$L^{2}$

a aparición sincrónica de un carcinoma de células renales y un tumor urotelial en un paciente es excepcional, no existiendo más de 50 casos publicados en la literatura, más infrecuente aún es la coincidencia de ambas neoplasias en la misma unidad renal, no estando descritos 30 casos en la bibliografia revisada.

\section{CASO CLÍnICo}

Varón de 78 años de edad sin antecedentes médicos ni quirúrgicos de interés. En estudio en consultas de urología por dolor lumbar de 6 meses de evolución con hematuria asociada. La exploración destaca percusión renal izquierda; respecto a las pruebas complementarias analitica de sangre normal, sedimento urinario leve microhematuria citología urinaria inespecífica. En ecografía se aprecia riñón izquierdo masa bilobulada de $5 \mathrm{~cm}$ de diámetro máximo, mesorrenal. La TAC destaca masa mesorrenal izquierda con protusión en seno de $6 \mathrm{~cm}$ de diámetro máximo, aneurisma de aorta infrarrenal de $5 \mathrm{~cm}$ de diáme- 
tro que abarca hasta la bifurcación de las iliacas; no se evidencian metástasis intraabdominales (Figs. 1 y 2). Con diagnóstico de tumor renal y aneurisma de aorta abdominal se realiza laparotomía abierta con corrección de aneurisma y colocación de prótesis de PTFE, nefrectomía izquierda con resección de uréter hasta cruce de la iliaca. El informe patológico informa de Riñón con dos tumores. Un carcinoma urotelial papilar y sólido, de alto grado, de pelvis y cálices renales con extensión superficial pero sin infiltración de la capa muscular piélica ni del parénquima renal; estadio pT1 (m) G2 según la UICC. Y un carcinoma de células renales tipo papilar con cambios oncocíticos, de bajo grado (Fuhrman 2), limitado al parénquima, sin afectación del sistema excretor ni venoso; estadio pT1b G2 según la UICC (Figs. 3, 4 y 5). Dada la edad del paciente, márgenes ureterales libres y sin displasia, no se realiza ureterectomía diferida. Un año tras la cirugía el paciente se encuentra asintomático y sin recidiva oncológica.

\section{DISCUSIÓN}

En 1921 Graves, describe el primer caso de tumor sincrónico, de carcinoma de células renales (CCR) y carcinoma transicional (CCT) en el mismo riñón. Setenta años más tarde, en 1993 Hart realiza, la revisión más amplia encontrando sólo 24 casos publicados en la literatura anglosajona ${ }^{1}$.

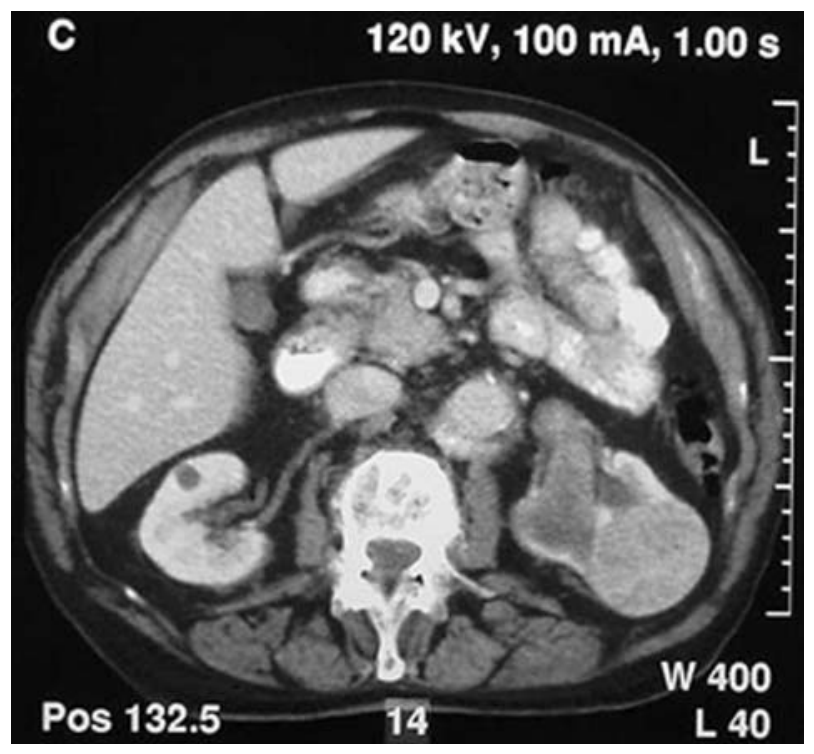

Figura 1. Tumor renal exofitico.

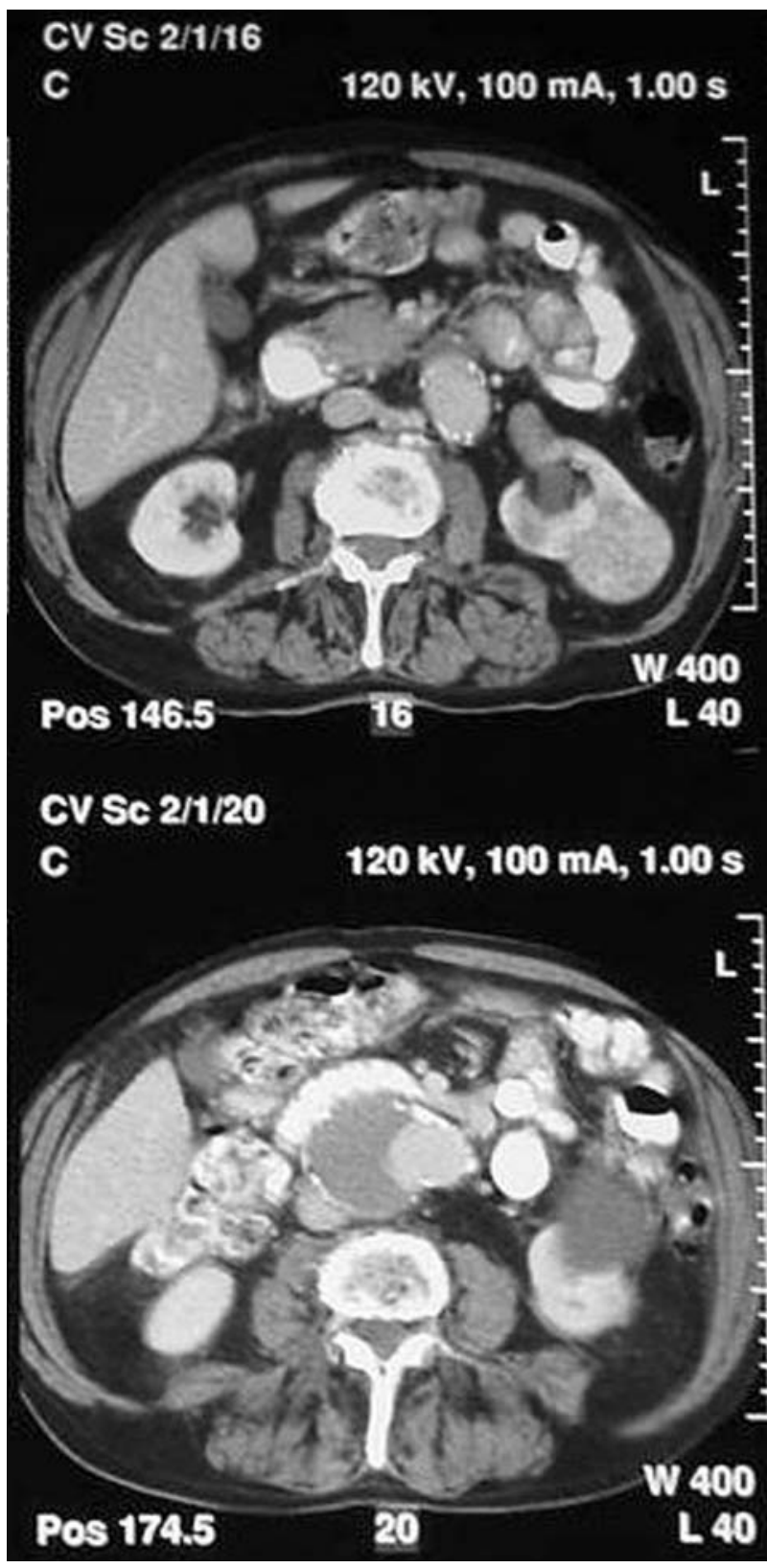

Figura 2. Tumor Renal y aneurisma de aorta.

Peyri et al en $1979^{2}$, comunican el primer caso en la literatura española. Merenciano en $2001^{3}$ encuentra un total de 44 tumores sincrónicos de CCR y CCT, incluyendo tumores uroteliales en pelvis, uréter y vejiga.

Diversos autores han publicado pacientes con tumores sincrónicos bilaterales, metacrónicos, asociación de carcinoma renal, con urotelial en uréter o vejiga, CCR con fibrosarcoma, existiendo casos de pacientes con tres neoplasias sincrónicas (CCR, CCT y linfoma) en la misma unidad renal ${ }^{3-6}$. 


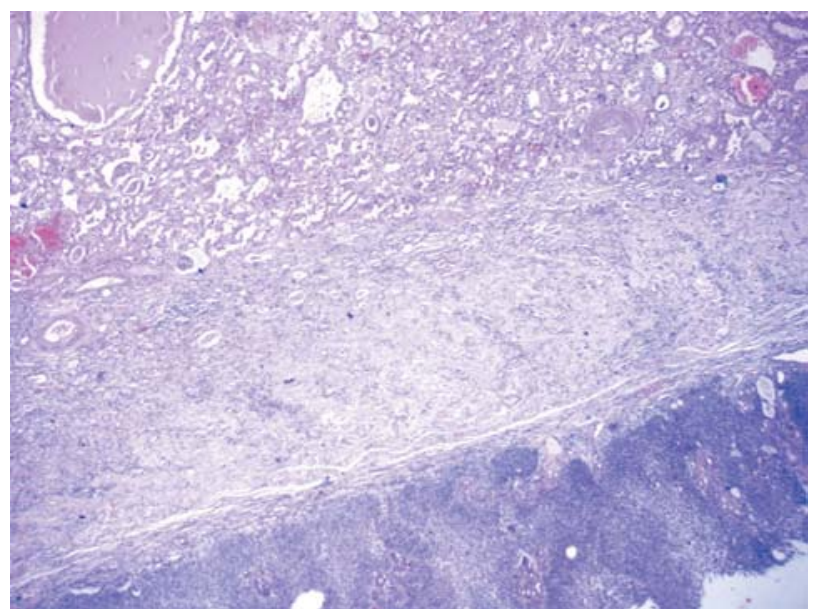

Figura 3. Detalle microscópico del tumor urotelial y del adenocarcinoma renal.

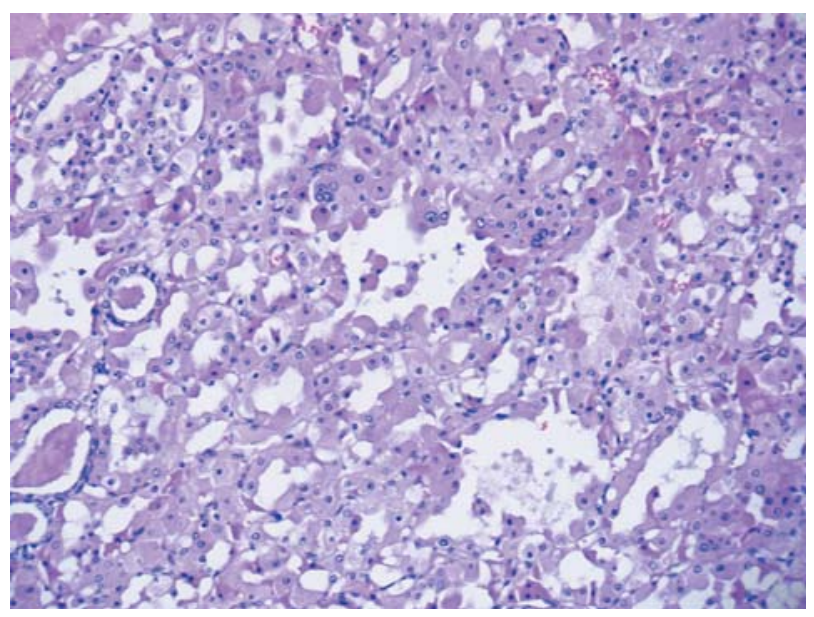

Figura 4. Microscopía óptica del carcinoma de células renales.

El CCR representan entre el 1 al 3\%, de los tumores; suponiendo el CCT el 7\% de las neoplasias del adulto. Dentro de los tumores renales, el $80 \%$ corresponden a carcinomas de células renales y el $7 \%$ a tumores de células transicionales ${ }^{1,3}$. La serie de hospital Anderson ${ }^{7}$, en un periodo de 30 años, con un total de 700 pacientes con CCR sólo encuentra un paciente con tumor sincrónico transicional en el mismo riñón, que supone una incidencia del $0,14 \%$.

La edad de aparición más frecuente es entre la $6^{\circ}$ y $7^{\circ}$ década de la vida, con una edad media de 64,5 años ${ }^{1,3-6,8}$, con predominio del sexo masculino, con una relación de 2:1, existiendo mayor afectación el riñón izquierdo (relación 3:1). Siendo el tabaquismo el único factor de riesgo compartido por ambos tumores ${ }^{1,9}$.
La hematuria es el sintoma dominante en más del 90\% de los casos, otros sintomas habituales son dolor lumbar, y sensación de masa ${ }^{1,3,5,6,8-10}$. Otros síntomas descritos son de urinoma secundarios a hidronefrosis ${ }^{5}$, pielonefritis enfisemato$\mathrm{sa}^{9}$, y hematoma retroperitoneal espontáneo.

El diagnóstico preoperatorio de ambos tumores es difícil, existiendo pocos casos con diagnóstico previo a la cirugia ${ }^{8}$. La ecografía informa de tumor renal, utilizando la TAC para confirmar el diagnóstico. La TAC suele informar de tumor renal no pudiendo diferenciar en múltiples ocasiones ambos tumores.

El diagnóstico definitivo lo aporta el estudio patológico. La mayor parte de los pacientes presentan tumores transicionales de bajo grado, aunque hay descritos casos de alto grado ${ }^{1,3,8}$. La pelvis renal es la localización más frecuente del CCR siendo inusual su aparición en los cálices ${ }^{1}$. Diversos estudios, no evidencian una mayor agresividad de los tumores cuando su presentación es de manera sincrónica que cuando debutan de manera aislada ${ }^{1,6,10}$, presentando en un $24 \%$ metástasis en el momento del diagnóstico ${ }^{1}$. Hart realiza un estudio inmunohistoquímico de tumores sincrónicos ipsilaterales de células renales y transicionales, evidenciando que ambos tumores presentan positividad para citoqueratinas y antígeno epitelial de membrana, siendo habitual la ausencia de sobreexpresión de la p53.

El tratamiento de elección es la nefroureterectomía, siempre que se diagnostique la existencia

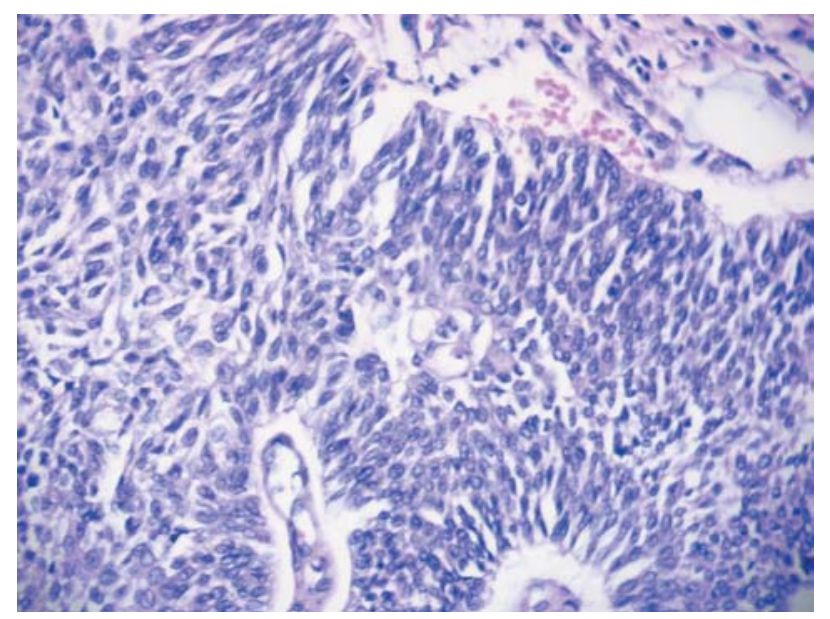

Figura 5. Microscopía óptica del carcinoma urotelial. 
de ambos tumores previo a la cirugía. La nefrectomía ha sido el tratamiento de elección en la mayoría de los casos. La ureterectomía diferida debe cuestionarse en pacientes de edad avanzada, márgenes ureterales libres, y en tumores de bajo grado ${ }^{3,8}$.

\section{CONCLUSIONES}

La coincidencia un CCR y un CCT de manera sincrónica en un mismo riñón es una situación excepcional no existiendo más de 30 casos publicados en la literatura médica mundial. La hematuria es el sintoma princeps. El diagnóstico preoperatorio es difícil, siendo el estudio patológico el que aporta el diagnóstico de certeza. La nefroureterectomía debe ser el tratamiento de elección siempre que se conozca el sincronismo tumoral; en caso de haberse realizado sólo nefrectomía, la ureterectomía diferida debe estar indicada en pacientes jóvenes, con márgenes ureterales positivos, y en tumores uroteliales de alto grado. El pronóstico de ambas neoplasias con presentación sincrónica es el mismo que, el de ambos tumores con presentación aislada.

\section{REFERENCIAS}

1. Hart AP, Brown R, Lechago J. et al. Collision of transicional cell carcinoma and renal cell carcinoma in a single kidney: an inmunohistchemical study and review of the literature. Cancer 1994;73:154-159

2. Peyri R, Ferrer Roca O, Mallafre JM et al. Carcinoma urotelial e hipernefroma renal en el mismo riñón. Actas Urol Esp 1979;3:105-106.
3. Merenciano Cortina FJ, Laforga J, De la Morena E, et al. carcinoma transicional de uréter y carcinoma ipsilateral sincrónico de células renales en riñón hidronefrótico: Asociación infrecuente. Actas Urol Esp 2001;25:380-384.

4. Villegas AC. Bilateral primary malignant renal tumors of dissimilar histogenesis: report of 2 cases. J Urol 1967;98: 450-455.

5. Fukasawa M, Kobayashi H, Matsushita K et al Intraperitoneal rupture of giant hydronephrosis due to ureteral cancer accompanied by renal cell carcinoma. J Urol 2002; 167:1393-1394.

6. Bernie JE, Albers L, Baird S, Parsons CL. Synchronous ipsilateral renal adenocarcinoma, transicional cell carcinoma of the renal pelvis and metastatic renal lymphoma. $J$ Urol 2000;164:773-774.

7. Von Esenbach DE, Johnson DE, Ayala AG. Simultaneous occurrence of renal adenocarcinoma and transicional cell carcinoma of the renal pelvis. J Urol 1977;116:105-106.

8. Ferrero Doria PL, Guzmán Martínez-Valls JP, Morga Egea $\mathrm{M}$, et al. Carcinoma de células transicionales y adenocarcinoma de células renales: caso inusual de asociación en el mismo riñón. Actas Urol Esp 1998;22:431-433.

9. Wang MC, Tseng CC, Lan RR et al. Double cancers of the kidney and ureter complicated with emphysematous pyelonephritis within the parenchyma of the renal tumor. Scand J Urol. Neprol 1999;33:420-422.

10. Wegner HE, Bornhoft G, Dieckmann KP. Renal cell cancer and concomitanttransitional cell cancer of the renal pelvis and ureter in the same kidney-report of 4 cases and review of the literature. Urol Int 1993;51:158-163.

Dr. I. Gómez García

María Tubau, 15 portal $3-1^{\circ}-3$

28050 Madrid

(Trabajo recibido el 7 abril de 2005) 